\title{
ESTIMATION OF EMULSIFIED AND DISSOLVED OIL CONTENT IN SEAWATER
}

\author{
Kamila Rudź, Henryk Toczek \\ Gdynia Maritime University \\ Faculty of Marine Engineering \\ Morska Street 81-87, 81-225 Gdynia, Poland \\ tel.: +4858 6901504, fax: +48586901399 \\ e-mail:k.rudz@wm.am.gdynia.pl,h.toczek@wm.am.gdynia.pl
}

\begin{abstract}
The demand to control the amount of oil discharged to the seawater is the consequence of increasing shipping activities. Oil products enter marine environment on daily basis in the form of fuels, engine oils or crude oils. Each of them have a significant impact on marine life and the coastal water management. Oil content influences many environmental factors, like water quality and bio-optical parameters (e.g. water-leaving radiance, inherent optical properties, seawater fluorescence). It should be measured on regular basis to avoid over or underestimation of those parameters. Currently there are several methods used to estimate the total hydrocarbon content in seawater, mostly based on fluorescence measurements. We present a unique method suitable to determine the concentration of oil products in two forms: the amount of dissolved oil and the amount of oil-in-water emulsion. The method consist of several steps: seawater sampling, vacuum filtering, extracting of oil in $n$-hexane, fluorescence measurements and calculation of oil concentration in comparison to the reference samples, i.e. the solutions of different types of crude oil in n-hexane. The results have been measured for the samples collected in Southern Baltic Sea during several ship cruises in 2012. We discuss the advantages and disadvantages of presented method in the context of radiative transfer modelling and potential remote detection of dispersed oil.
\end{abstract}

Keywords: Fuel, Oils \& Lubrication, Exhaust Emission \& Ecology

\section{Introduction}

Natural composition of seawater is remarkably affected by many sorts of pollutants since the expansion of maritime transportation. One of the greatest threats to marine ecosystem is oil pollution, which causes barely reversible sequence of changes influencing seawater quality and marine life. Oil pollution in the sea is therefore not only a subject of scientific interest, but it is also an issue of public concern. As a consequence of increasing refinery products global demand, the International Maritime Organization (IMO) has been working to prevent this kind of pollution in the frame of MARPOL (International Convention for the Prevention of Pollution from Ships), since the early seventies of $20^{\text {th }}$ century. In 1974 the first Baltic Marine Environment Protection Commission signed the Helsinki Convention to deal with growing pollution loads to the Baltic Sea, including oil pollution. Also the European Union created a law on the disposal of waste oils (Council Directive 87/101/EWG) in order to limit their negative influence to the marine environment. Oil loads to the world's ocean were estimated for over 3 million tons per year [8].

In the global scale, the most significant amounts of oil enter the seas with river inflows. Therefore the estuaries of big rivers flowing through the industrial and agricultural areas are the most endangered zones. The next remarkable source of oil pollution is daily aircraft and shipping activity, including crude oil exploitation and transportation. This is why oil fields and ship routes are very exposed to oil contamination. Moreover, in some marine regions natural bottom seeps contribute to the total oil content. Oil from this sources forms a thin surface film, if the concentration is higher than $50 \mathrm{ppm}$. Lower concentrations partly dissolve and partly disperse in seawater, becoming oil-in water emulsion. Oil emulsion amounts to over $80 \%$ of the total oil 
pollution in Baltic Sea estimated for 76 thousand tons per year [3-5]. According to the MARPOL convention, ship discharge waters may legally contain up to $15 \mathrm{ppm}$ of oil. In some regions the limits are more restricted (e.g. up to $5 \mathrm{ppm}$ in Canadian inland waters) [6].

The presence of emulsified and dissolved oil is currently not taken into account in radiative transfer models or algorithms for retrieval of seawater parameters [15]. The study presents a unique method suitable to determine the concentration of oil products in seawater in two forms: the amount of dissolved oil and the amount of oil-in-water emulsion. The method is applicable for all seawater samples, but is mostly useful for samples taken from coastal zones, estuaries, main marine transportation routes and oil extraction areas.

\section{Methods for detection of oil pollution}

Huge tanker accidents resulting in millions of tons of crude oil spilled in the seas have demanded the development of oil detection and identification methods. In order to minimize the damages, global and local oil spill rapid response systems were organized. They usually base on satellite microwave radar detection conducted by scatterometers or synthetic aperture radars, and on airborne measurements by side-looking airborne radars. Oil spill detection is often supported by UV specific fluorescence sensors or IR brightness temperature sensors [21].

\subsection{Space-borne detection}

The vast majority of scientific research focuses on dealing with oil spills. Currently there is several methods developed for oil spill detection. Satellite remote sensing provides rapid, frequent, and synoptic measurement of the ocean's surface waters, and thus has been used widely to monitor oil pollution at sea, as well as in lakes. Space-borne radar methods base on the damping of short wind-generated gravity-capillary waves by the oil film on the sea surface. The backscattered radio or microwave signal is lower for the sea surface covered by oil than for the unpolluted area. The difference is usually measurable at the wind speeds from 2 to $12 \mathrm{~m} / \mathrm{s}$, however it is optimal for 5-6 $\mathrm{m} / \mathrm{s}$. The instruments used to measure the backscattered microwave signal are scatterometers and synthetic aperture radars. They differ with the coverage, resolution, signal frequency and polarization and are currently applied to detect oil spills operationally (all-weather day and night detection) in the open ocean waters as well as in the coastal areas [11].

Another space-borne method bases on the radiometric detection of an enhanced sun glint caused by oil slick. This method is applicable only in a specific configuration between radiometer's viewing angle and sun height. It is useful to support radar techniques and monitor spotted spills. Specifically, satellite sensors are used for preliminary oil spill assessment while airborne sensors are used for detailed oil spill analysis.

\subsection{Airborne detection}

Airborne oil spill remote sensing is divided into two different modes of operation: far-range detection and near-range monitoring for suspicious areas. Far-range detection is performed by a side-looking airborne radar (SLAR), which has a higher spatial resolution than space-borne sensors. Near-range monitoring of oil spills includes mapping of relative and absolute oil layer thickness, as well as classification of the type of oil. There is a number of near-range sensors, such as infrared or ultraviolet line scanners, visible line scanners, camera systems, microwave radiometers and laser fluorosensors [12]. They can measure the returning laser signal with a characteristic oil fluorescence, or the attenuation of Raman scattering on the oil film. The intensity of fluorescence is proportional to the oil slick thickness. Detectability of oil films is therefore limited to the thickness from $20-70 \mu \mathrm{m}$ by airborne IR-sensors to several $\mu \mathrm{m}$ by shipborne lidars (during day and night time). UV-scanners give the possibility to detect the slicks 
from 0.1 to $10 \mu \mathrm{m}$, but only in the daylight. Operational airborne oil spill detection is based on combination of different techniques.

In the last decade some investigations focused on the fact, that optical properties of an oil slick vary in time. The process of oil dispersion and emulsification begins soon after the discharge and its speed depends on the sea roughness. Oil spills first transform into the water-in-oil emulsion, and then, with the increase in spreading and mixing, the water-in-oil emulsion can become an oilin-water emulsion. Infrared sensors are unable to detect oil emulsions containing $70-80 \%$ of water, because its thermal properties are similar to the surrounded water. Also ultraviolet and microwave sensors fail. However, there are several studies showing that laser fluorosensor might be successful in detection of high concentrated oil emulsion [9]. Fluorescence properties of water-in-oil emulsion are different than for a continuous oil film. Moreover, in case 2 waters the fluorescence of CDOM coincide with the fluorescence of oil and it is difficult to separate them. In consequence, oil content in seawater can lead to misestimating of the organic matter concentration calculated from remote sensing algorithms as long as its properties are not taken into consideration. Emulsification of some types of oil can cause an increase in fluorescence signal and for others - a decrease. The effect seems to depend also on the thickness of emulsified layer [1]. There is relatively poor attention attracted to the detection of dispersed or dissolved oil. The missing knowledge is a challenge for further investigations of oil-in-water emulsions.

\subsection{Laboratory detection}

Oil is a luminescent medium which fluoresces in the range from ultraviolet to infrared. In the sixties and seventies of $20^{\text {th }}$ century there was a bloom of research on oil fluorescence. The possibility of using fluorescence to detect and identify crude oil was reported in the early 1970s. As a result, dozens of independent, but conceptually similar methods were developed, generally based on aromatic hydrocarbon fluorescence measurements, e.g. [2, 7, 10]. The application of these methods on regular basis failed because of the time consumption and costs involved. Today the concentration of oil products in seawater is monitored irregularly and only in some areas [18]. It can be indicated using expensive gas chromatography, fluorescence extraction [19] or timeresolved in situ methods [20] and sensors (e.g. Turner Cyclops-7, LISST-100X). In this study we present a unique method suitable to determine the concentration of oil products in two forms: dissolved oil and the oil-in-water emulsion.

\section{Material And Method}

Measurements were conducted for seawater samples collected in Southern Baltic Sea during several ship cruises in 2012 onboard r/v Oceania from the Institute of Oceanology of Polish Academy of Sciences (Fig. 1). Samples from each station were divided into two parts. One part was prepared directly for further total hydrocarbon estimation, and the other part was filtered using vacuum filtering system with a cellulose filter (permeability $0.45 \mu \mathrm{m}$ ) for dissolved hydrocarbon estimation. Reference samples were prepared in the form of solutions of different types of crude oil: Petrobaltic, Romashkino, Flotta, in n-hexane in concentration of $5 \mathrm{ppm}$. Hexane extracts of seawater samples were prepared using $1200 \mathrm{ml}$ of seawater and $15 \mathrm{ml}$ of n-hexane. They were shaken for $20 \mathrm{~min}$ on laboratory shaker $358 \mathrm{~S}$ and stabilized for 24 hours in room temperature.

Determination of hydrocarbon content in these samples was carried out using comparative fluorescence method [17] on spectrofluorimeter Shimadzu RF-5301PC. All samples were excited by the light wavelength $240 \mathrm{~nm}$, and the emission of fluorescence signal was measured at the wavelength $320 \mathrm{~nm}$. These wavelengths were chosen as the most sensitive for this method on the basis of previous measurements. The concentrations $\mathrm{C}_{\mathrm{s}}$ of oil hydrocarbons in unfiltered and filtered seawater samples were calculated separately for each reference oil sample according to the formula: 


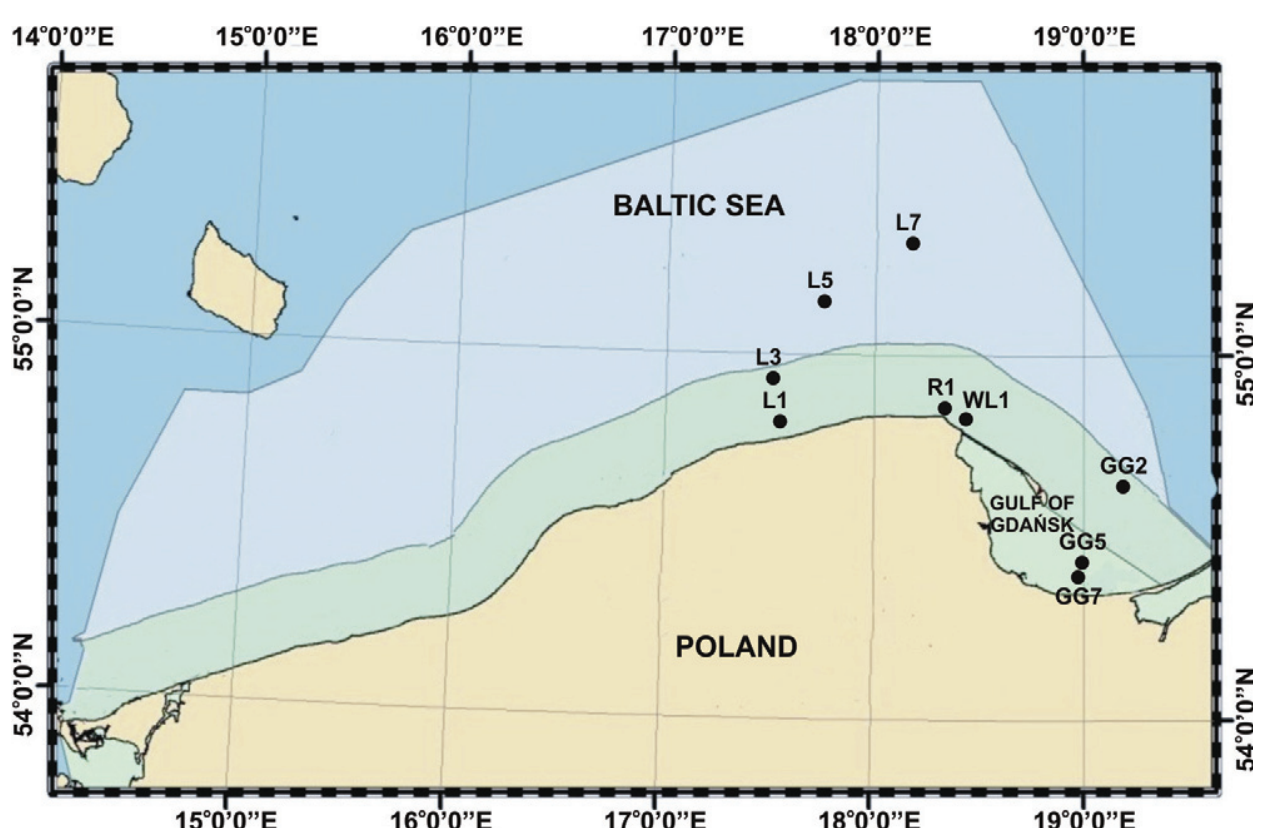

Fig. 1. Map of stations of collected seawater samples

$$
C_{s}=\frac{F_{s}}{F_{r e f}} \cdot \frac{m_{h e x}}{m_{s w}} \cdot C_{r e f},
$$

where:

$F_{s}$ - fluorescence of the sample (seawater extracted in n-hexane),

$F_{\text {ref }}$ - fluorescence of the reference sample,

$m_{h e x}$ - mass of hexane used for extraction,

$m_{s w}$ - mass of seawater,

$C_{r e f}$ - concentration of reference sample.

The total hydrocarbon content is assumed to be the sum of dissolved and dispersed oil. Vacuum filtration removes oil droplets (as well as other particles larger than $0.45 \mu \mathrm{m}$ ) from seawater. Filtered samples contain therefore dissolved hydrocarbons and hydrocarbon aggregates smaller than $0.45 \mu \mathrm{m}$ (the mean size of an oil hydrocarbon particle is $0.1 \mu \mathrm{m}$ ). The main source of uncertainties in this method is the necessity of comparison to the reference sample, which may contain different types of hydrocarbons. To minimize this uncertainty 3 different reference crude oils were chosen.

\section{Results And Discussion}

Below, we present the exemplary fluorescence spectra of the samples prepared from unfiltered and filtered seawater as well as the spectra of reference samples (Fig. 2.). Unfiltered seawater was used to measure the total concentration of crude oil, while the filtered seawater brought the information on the amount of dissolved hydrocarbons. The peak of Raman scattering (485 $\pm 15 \mathrm{~nm}$ ) was removed.

Concentrations of hydrocarbons originating from crude oils in natural seawater usually vary from several ppb to several ppm. In the samples collected for this study, oil content was relatively low, it did not exceed $0.2 \mathrm{ppm}$. The quantitative results are presented in the Tab. 1. The stations: GG2, GG5, WL1, R1, and L5 were characterized by a significant advantage of emulsified oil content over the dissolved part. Such situation is typical for natural seawater, especially in the coastal regions, exposed for dispersed oil pollution from different sources [13]. The dispersed oil amounts to $60 \%-95 \%$ of the total oil content, and its contribution increases with oil contamination. Next two stations: L1 and L7, represent the situation of approximately equal 

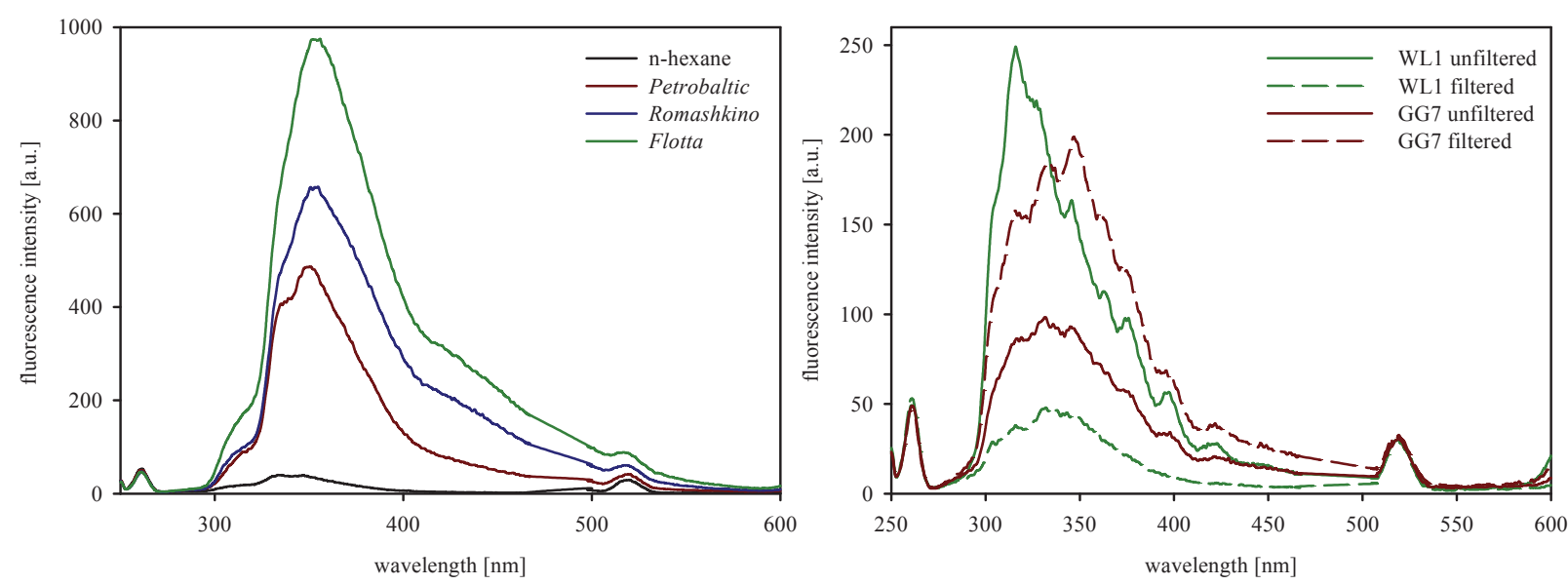

Fig. 2. Left graph: Fluorescence spectra of pure n-hexane and reference samples: hexane extracts of Petrobaltic, Romashkino and Flotta crude oils. Right graph: Examples of fluorescence spectra (excitation: $240 \mathrm{~nm}$ ). Samples WL1 represent seawater containing more emulsified than dissolved oil, while in samples GG7 dominates the dissolved oil

amount of dispersed and dissolved oil concentrations. This usually occurs in the relatively clean coastal waters, exposed in a minor degree for dispersed oil pollution. Stations GG7 and L3 are the rare examples of a higher dissolved oil content, which may happen in regions rarely exposed for dispersed oil pollution. The size distribution of oil droplets changes significantly in time. Droplets break in the bulk of sea and become smaller [14], till they spread and either fall to the seabed or dissolve in seawater.

The concentration of crude oil calculated using the comparative method depends on the choice of the reference sample. It means that the result is á priori the concentration of the mixture of hydrocarbons present in the reference crude oil. The difference between Petrobaltic and Romashkino crude oils stayed within $1 \%$, but comparison to crude oil Flotta gives almost $40 \%$ lower values. For this reason it is important to choose the most suitable oil or a mixture of oils as the reference sample.

Tab. 1. Concentrations of emulsified and dissolved oil in ppb

\begin{tabular}{c|ccc|ccc}
\hline Station & Petrobaltic & $\begin{array}{c}\text { Emulsified oil } \\
\text { Romashkino }\end{array}$ & Flotta & Petrobaltic & $\begin{array}{c}\text { Dissolved oil } \\
\text { Romashkino }\end{array}$ & Flotta \\
\hline & & & & & & \\
GG2 & 18.01 & 18.18 & 11.49 & 9.13 & 9.22 & 5.83 \\
GG5 & 50.56 & 51.06 & 32.27 & 39.03 & 39.41 & 24.91 \\
WL1 & 162.50 & 164.10 & 103.71 & 7.78 & 7.86 & 4.96 \\
R1 & 138.96 & 140.33 & 88.69 & 94.40 & 95.33 & 60.25 \\
L5 & 138.97 & 140.33 & 88.69 & 53.74 & 54.27 & 34.30 \\
& & & & & & \\
L1 & 88.11 & 88.98 & 56.24 & 81.00 & 81.80 & 51.70 \\
L7 & 56.89 & 57.45 & 36.31 & 55.05 & 55.59 & 35.13 \\
& & & & & & \\
GG7 & 30.54 & 30.84 & 19.49 & 65.37 & 66.02 & 41.72 \\
L3 & 33.61 & 33.94 & 21.45 & 81.26 & 82.06 & 51.86
\end{tabular}




\section{Summary}

The contamination of seawater with oil products influences many environmental factors, like water quality and bio-optical parameters (e.g. water-leaving radiance, inherent optical properties, seawater fluorescence). The concentration of oil should be measured on regular basis to avoid over or underestimation of such parameters [16]. Presented method for detection of emulsified and dissolved oil content in seawater can be involved into marine radiative transfer modelling and marine ecosystem modelling. In the regions, where oil products are constantly present in seawater in detectable concentrations, they should be considered as seawater constituents. It is important to distinguish between various forms of oil content in seawater, because their impact to biophysical and chemical processes is different. Dissolved oil mostly affects the chemical reactions, influences marine life and water quality factors. On the other hand, emulsified oil causes changes in the light propagation in the bulk of sea, because it absorbs and scatters light. The knowledge about the concentration of dispersed oil is therefore a significant input data for further radiative transfer analysis, both in modelling and remotely sensed radiometric measurements. It can contribute to remote detection of dispersed oil. The method can be only applied locally and gives near real-time data, as it requires taking the sample of seawater and minimum 48 hours of time.

\section{Acknowledgements}

Authors would like to thank Janina Heldt (University of Gdansk) for making the spectrofluorimeter available for this study and Emilia Baszanowska (Gdynia Maritime University) for practical advice on oil fluorescence. Special thanks we address to Marek Józefowicz (University of Gdansk) for helpful assistance during measurements and inspiring discussions on the aspects of fluorescence. The study was supported by the Gdynia Maritime University grant no. 08/BMN/M/2013.

\section{References}

[1] Drozdowska, V., Analysis of variability of surface waters fluorescence spectra using lidar method (in Polish), Ph. D. thesis, Inst. Oceanol. PAS, Sopot 2005.

[2] Frank, U., Jeleniewski, H., A Method For Quantitating Oil Directly In Water By Fluorescence Spectrophotometry, Epa Anal. Qc Newsletter, 18, 1973.

[3] GESAMP (Joint Group of Experts on the Scientific Aspects of Marine Pollution), Impact of oil and related chemicals and wastes on the marine environment, Reports and Studies, 50, 1993.

[4] GESAMP, Estimates of oil entering the marine environment from sea-based activities, Reports and Studies, 75, 2007.

[5] GMOPIG (Global Marine Oil Pollution Information Gateway), http://oils.gpa.unep.org/.

[6] HELCOM (Helsinki Commission, Baltic Marine Environment Protection Commission), http://www.helcom.fi/, 2011.

[7] Hornig, A. W., Identification, Estimation And Monitoring Of Petroleum In Marine Waters By Luminescence Methods, Proc. Nbs Symp., Nbs Spec. Publ., 409, 135-137, 1974.

[8] International Convention for the Prevention of Pollution from Ships MARPOL 73/78, IMO (International Maritime Organization), Polish Ship Register, Gdańsk 1997.

[9] Jha, M. N., Levy, J., Gao, Y., Advances in Remote Sensing for Oil Spill Disaster Management: State-of-the-Art Sensors Technology for Oil Spill Surveillance, Sensors, 8, pp. 236-255, 2008.

[10] Keizer, P. D., Gordon, D. C., Detection Of Trace Amounts Of Oil In Sea Water By Fluorescence Spectroscopy, J. Fish. Res. Board Can., 30, 1039-1046, 1973.

[11] Migliaccio, M., Gambardella, A., Tranfaglia, M., Sar Polarimetry To Observe Oil Spills, Ieee Trans. Geosci. Remote. Sens., 43 (2), 506-511, 2007. 
[12] Robbe, N., Zielinski, O., Airborne remote sensing of oil spills-analysis and fusion of multispectral near-range data, J. Mar. Sci. Environ., C2, 19-27, 2004.

[13] Rudź, K., Baszanowska, E., Rohde, P., Zielinski, O., Fluorescence Methods and Monte Carlo Radiative Transfer Simulation Applied to Oil Detection in Baltic Sea, Joint Proceedings, 24, Bremerhaven 2011.

[14] Rudź, K., Darecki, M., Toczek, H., Modelling of Seawater Polluted by Light and Heavy Crude Oil Droplets, Journal of KONES Powertrain and Transport, Vol. 19, No. 2, pp. 473-480, Warsaw 2012.

[15] Rudź, K., Emulsified Fuels of Machine Origin in Seawater - a Contribute to Remote Detection, Journal of KONES Powertrain and Transport, 18(3), Warsaw 2011.

[16] Rudź, K., Modelling of Seawater Polluted by Light and Heavy Crude Oil Droplets, Journal of Polish CIMAC, Vol. 7, No. 1, Warsaw 2012.

[17] Stelmaszewski, A., The contribution of fluorescence to measurements of light scattering in oil-in-water emulsions, Oceanologia 53 (2), pp. 549-564, 2011.

[18] Stelmaszewski, A., Determination of petroleum pollutants in coastal waters of the Gulf of Gdansk, Oceanologia, 51(1), 85-92, 2009.

[19] Stelmaszewski, A., Fluorescence method for determination of oil identity, Optica Appl., XXXIV (3), 2004.

[20] Zielinski, O., Dittmar, T., Rohde, P., Ungermann, R., Voss, D., CDOM and PAHs in the Marine Environment - in situ Sensing with Time Resolved Fluorescence and Liquid Core Waveguides, Ocean Optics XX, Anchorage 2010.

[21] Zielinski, O., Hengstermann, T., Robbe, N., Detection Of Oil Spills By Airborne Sensors, in: Marine Surface Films, edited by: Gade, M., Huehnerfuss, H., Korenowski, G. M., Springer, 255-271, 2006. 
